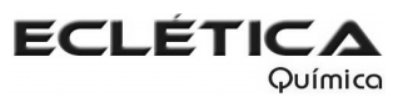

www.scielo.br/eq

www.ecletica.iq.unesp.br

Volume 33, número 4, 2008

\title{
Determination of phenolic compounds and evaluation of antioxidant capacity of Campomanesia adamantium leaves
}

\author{
I. D. Coutinho', R. G. Coelho', V. M. F. Kataoka ${ }^{2}$, N. K. Hondal, J. R. M. Silva , \\ W. Vilegas ${ }^{3}$ and C. A. L. Cardoso ${ }^{1,2, *}$ \\ ${ }^{1}$ Universidade Federal de Mato Grosso do Sul, Departamento de Química, \\ Caixa Postal 549. 79070-900, Campo Grande/MS. Brazil \\ ${ }^{2}$ Universidade Estadual de Mato Grosso do Sul, Curso de Química, \\ Caixa Postal 351, 79804-970, Dourados/MS, Brazil \\ ${ }^{3}$ Universidade Estadual Paulista, Departamento de Química Orgânica, \\ Caixa Postal 355, 14801-970, Araraquara/SP, Brazil \\ *claudia@uems.br
}

\begin{abstract}
Five flavanones and three chalcones were isolated from Campomanesia adamantium Berg. (Myrtaceae) leaves. The contents of these compounds were determined by HPLC. The phenolic contents were also determined. The monitoring of the antioxidant activity was carried out by inhibition of peroxidation using the linoleic acid system and radical-scavenging (DPPH). The plants were collected from 4 distinct cities of the Mato Grosso do Sul State, Brazil. The different samples exhibited a range of 4.67-232.35 mg/g chalcones and 15.62-50.71 mg/g flavanones and phenolic contents of the 7.24-21.19 mg/g gallic acid. All extracts showed high antioxidant activity with a wide range of the radical-scavenging (DPPH) from 52.0 to $92.2 \%$ and inhibition oxidation of linoleic acid from 14.6 to $94.2 \%$.
\end{abstract}

Keywords: Campomanesia adamantium; Chalcones; Flavanones; Antioxidant activity..

\section{Introduction}

Many plants used in folk medicine contain a wide variety of phenolic compounds. The phenolic compounds act in the scavenging of free radical and in the inhibition of lipid peroxidation, especially the flavonoids [1]. Epidemiological studies support the belief that flavonoids in the human diet can reduce the risk of various cancers, especially hormone-dependent breast and prostate cancer [2]. Studies "in vitro" activity of flavanones and chalcones demonstrated that these compounds have antitumoral effects [3]. The chalcones also exhibit numerous beneficial activities such as antibacterial, antifungal, antiinflammatory, antileishmanial, antimalarial [4] and anti-HIV protease [5].

Given the importance of dietary habits and food components to health, studies of the identification of compounds in plants associated 
with antioxidant activity are important to support the protective status of fruits and vegetables for people. The chemical composition and antioxidant activity of the Campomanesia species, a Brazilian "Cerrado" plant, has been investigated by our group.

Campomanesia adamantium (Myrtaceae) is a small tree with edible fruit and commonly known as guavira or guabiroba [6]. The fruits and leaves are widely used to make liqueurs, juices and sweets. In popular medicine the leaves are used as depurative, anti-diarrhoeic, cleanser, antirheumatic and reducer of blood cholesterol [7] and the roots are also used by people in the treatment of diabetes.

The HPLC technique has been shown to be a very efficient system for separating complex mixtures of plants. HPLC methods have been reported for the determination of substances and for monitoring variation in the composition of samples $[8,9]$. A procedure suitable for HPLCUV analysis of flavanones and chalcones contents in C. adamantium, has been developed by this research team.

This paper describes the isolation of flavanones and chalcones and the evaluation of antioxidant activity from $C$. adamantium leaves during flowering stage. And also the quantification of these compounds, the determination of the phenolic contents and antioxidant activity in samples collected from four cities of the Mato Grosso do Sul State, Brazil during fruit bearing stage.

\section{Materials and methods}

\section{Chemical and spectral measurements}

Materials used and the suppliers were: quercetin, gallic acid, 2,6-Di-tert-butyl-4methylphenol (BHT), naringenin, 2,2-diphenyl1-picryl-hydrazil (DPPH) and linoleic acid were obtained from Sigma-Aldrich; folin-Cicauteau from Merck; $\beta$-carotene from Calbiochem; tanic acid from CETUS; chloroform-d from Cambridge Isotope Laboratories, Inc; spectroscopy-grade acetonitrile and methanol were purchased from Merck (Darmstadt. Germany); water was purified using a Milli-Q system (Millipore). The solvents employed in other analyses were grade analytic. NMR 1D and 2D spectra were recorded in chloroform-d used as an internal reference, employing a Bruker DPX-300 $\left({ }^{1} \mathrm{H} 300 \mathrm{MHz} ;{ }^{13} \mathrm{C} 75 \mathrm{MHz}\right)$. The antioxidant activity assays were recorded in $\mathrm{MeOH}$, employing $700 \mathrm{~S}$ Femto UV Spectrophotometer of 517 $\mathrm{nm}$ wavelength. Column chromatography was performed with Kieselgel 60 (70-230 mesh. Merck). Preparative TLC was carried out on silica gel $\mathrm{PF}_{254}$. Spots were visualized under ultraviolet light of $254 \mathrm{~nm}$ wavelength, sprayed with $p$ anysaldeyde and heated. Sephadex LH-20 (Pharmacia) was used for GPC.

\section{The collection of the vegetable material}

For the phytochemical work, the leaves of the $C$. adamantium were colleted in Mato Grosso do Sul State, Brazil, in the city of Jardim (CAIF latitude $21^{\circ} 25^{\prime} 02.0 " \mathrm{~S}$ and longitude $056^{\circ} 13^{\prime \prime}$ $77.0^{\prime \prime} \mathrm{W}$ ) during the flowering stage. For quantification and chemistry analyses the leaves were collected in the cities of Dourados (CAE; latitude $22^{\circ} 11^{\prime} 813$ " S and longitude $054^{\circ} 55^{\prime} 801^{\prime \prime} \mathrm{W}$ ); Bela Vista (CAL; latitude $22^{\circ} 06^{\prime} 35.8^{\prime \prime} \mathrm{S}$ and longitude $056^{\circ} 33^{\prime} 00.8^{\prime}$ ' W); Bonito (CAB; latitude $21^{\circ} 07^{\prime} 50.0^{\prime \prime} \mathrm{S}$ and longitude $056^{\circ} 24^{\prime}$ $68.0^{\prime \prime} \mathrm{W}$ ) and Jardim (CAI; latitude $21^{\circ} 25^{\prime}$ 02.0 " S e longitude $056^{\circ} 13$ " 77.0 " W) during the fruit bearing stage. The species were identified by Marcos Sobral (UFMG) and voucher specimens 5196 (Dourados), 5198 (Bela Vista), 5197(Bonito) and 5195 (Jardim) have been deposited in the Herbarium of Mato Grosso do Sul - HMS, Campo Grande, MS, Brazil.

\section{Isolation of chemical constituents and purification}

The air-dried and powdered $C$. adamantium leaves $(804.19 \mathrm{~g})$ collected in the city of Jardim (CAIF), were extracted exhaustively with hexane, chloroform and methanol at room temperature (seven days for each solvent). The solvent was removed from the extract under vacuum yielding the hexane (5.32 g), chloroform (8.86 g) and methanol (58.88 g) extracts. For this paper only the methanol extract is discussed. The methanol extract (EM) was partitioned using water/hexane $(1: 1 \mathrm{v} / \mathrm{v})$ and water/ethyl acetate $(1: 1 \mathrm{v} / \mathrm{v})$. From that liquid-liquid partition were obtained the hexane phase and a mixture of the 
three phases denominated ethyl acetate phase, water phase and inter-phase IP, the latter phase being insoluble in ethyl acetate and water.

The sample IP (675.60 mg) was dissolved in $15 \mathrm{~mL}$ of methanol/ethyl acetate and fractionated by Sephadex LH-20 CC $(3.5 \mathrm{~cm}$ x $40 \mathrm{~cm})$ and eluted with methanol/ethyl acetate isocratyc systems. Two-hundred and five fractions of 10 $\mathrm{mL}$ were collected and were combined according to their behavior using TLC $\mathrm{F}_{254}$ in hexane/ethyl acetate/chloroform $(4: 4: 2 \mathrm{v} / \mathrm{v} / \mathrm{v})$. The fractions 46-51 and 60-62 were purified on CC using silica gel $70-230$ mesh $(1.5 \mathrm{~cm} \times 15 \mathrm{~cm})$ and eluted with toluene/ethyl acetate/ethanol gradient systems. Compounds $\mathbf{1}$ and $\mathbf{2}$ were isolated from fractions 46-51 and compounds 3, 4, 5, 6 and 7 were isolated from fractions 60-62. The fractions 90-98 were purified in CC using silica RP18 (1.5 $\mathrm{cm} \times 15 \mathrm{~cm})$ and eluted with water/acetonitrile/methanol gradient systems, resulting in the isolation of compound 8. All compound structures were determined by NMR 1D and 2D and compared with data in the literature [5, 10-15].

Preparation of the extracts from the plant collected in different regions for quantitative chemical analyses

For the antioxidant activity assay in ME and IP the samples were prepared from $20 \mathrm{mg}$ in $10 \mathrm{ml}$ of methanol. Samples CAE, CAL, CAI and CAE collected during the fruit bearing stage were prepared with $50 \mathrm{mg}$ of leaves in $25 \mathrm{~mL}$ methanol (maceration in sonication for two hours), filtered through a Milex filter $(0.22 \mu \mathrm{m}$ diameter pore) and reconstituted in a $25 \mathrm{~mL}$ volumetric flask with methanol $(n=3)$ for the determination of phenolic contents, antioxidant activity and the quantification of flavonones and chalcones.

Determination of the flavanones and chalcones contents by HPLC

\section{Analysis by HPLC}

The methanolic extracts obtained from $C$. adamantium leaves collected during the fruit bearing stage were analysed by an analytical HPLC (Varian 210) system with a ternary solvent delivery system, equipped with an autosampler and a photodiode array detector. The Star WS
(Workstation) software was used for chromatograms and measuring peak areas. The HPLC column was a RP18 $(25 \mathrm{~cm} \times 4.6 \mathrm{~mm} \times 5 \mu \mathrm{m})$ reversed-phase column, with a small precolumn $(2.5 \mathrm{~cm} \times 3 \mathrm{~mm})$ containing the same packing, used to protect the analytical column. Elution was carried out with a gradient solvent program of methanol/water/acetonitrile (40:50:10) taking 40 minutes to reach $80 \%$ methanol, $10 \%$ water and $10 \%$ acetonitrile, returning after that in 20 minutes to the initial conditions. The flow rate of $1.0 \mathrm{~mL} / \mathrm{min}$ and the volume injected was of 50 $\mu \mathrm{L}$. All chromatographic analyses were performed at $22^{\circ} \mathrm{C}$.

The quantification of flavanones and chalcones

The estimation of the contents of compounds $2,3,4,5,6,7$ and 9 , the last compound was isolated from Campomanesia pubescens fruits [16], in the samples CAE, CAB, CAI and CAL, was performed by external calibration. The standards (2-7 and 9) were purified by HPLC (purity was $\geq 90 \%$ ) as is standard for HPLC analysis.

In this study the compounds were dissolved separately in spectroscopy-grade methanol in order to obtain stock solutions, which were appropriately diluted in 5 concentrations for each substance. Aliquots $(50 \mu \mathrm{L})$ of 5 dilutions for each standard were analyzed by HPLC $(n=3)$. For each standard was obtained a corresponding chromatogram and a graphic plot was constructed of the means of areas made against the weight of each substance. Linear least squares regression of the peak areas as a function of the weight was performed to determine correlation coefficients. The equation parameters (slope and intercept) of each standard curve were used to obtain concentration values for samples.

\section{Determination of the phenolic contents}

Aliquots of $0.1 \mathrm{~mL}$ samples of CAE, CAB, CAI and CAL were mixed with $0.5 \mathrm{~mL}$ (1/10 dilution) of the Folin-Cicauteau reagent and $1 \mathrm{~mL}$ of ultrapurified water. The solutions were mixed and incubated at room temperature for $1 \mathrm{~min}$. After 1 min, $1.5 \mathrm{~mL}$ of $20 \%$ sodium carbonate solution was added and incubated at room temperature for $40 \mathrm{~min}$. The reaction mixture absorbance was measured at $760 \mathrm{~nm}$ on a spectrophotometer. The 
blanks were prepared with all the reagents except the sample. Gallic acid was chosen as a standard using 6 point standard curve $(10,50,100,150,300$ and $400 \mu \mathrm{g} / \mathrm{mL}$ ). All the tests were conducted in triplicate. The data were expressed as milligram gallic acid/g extract.

\section{Determination of the antioxidant activity}

Free radical scavenging activity (DPPH)

The free radical scavenging assay of samples ME and IP in the concentrations of 10.0, 20.0, 40.0, 80.0 and $160.0 \mu \mathrm{g} / \mathrm{mL}$ and samples CAL, CAI, CAB and CAE in the concentrations of $160.0,480.0,800.0$ and $1120.0 \mu \mathrm{g} / \mathrm{mL}$ were determined based on their ability to react with the stable DPPH free radical. The assay was carried out with aliquots of $1 \mathrm{~mL}$ of each sample added to $2 \mathrm{~mL}$ of a methanol solution of 2.2-diphenyl-1picryl-hydrazyl (DPPH) $0.004 \%$ and the mixture was incubated at a temperature of $25^{\circ} \mathrm{C}$ for 30 min and the absorbance of each solution was determined at $517 \mathrm{~nm}$. The scavenging effect of the radical of each sample was calculated and compared with the scavenging effect of quercetin, naringenin, BHT and tanic acid in the concentrations of 10.0, 20.0, 40.0, 80.0 and 160.0 $\mu \mathrm{g} / \mathrm{mL}$. All the tests were conducted in triplicate. The scavenging effect of the DPPH radical was calculated using the following equation [17]:

DPPH scavenging effects $(\%)=\left[\left(\mathrm{Ao}-\left(\mathrm{A}-\mathrm{A}_{\mathrm{A}}\right)\right) /\right.$ Ao] x 100

Ao is $\mathrm{A}_{517}$ of DPPH without a sample (control). $\mathrm{A}$ is $\mathrm{A}_{517}$ of a sample and DPPH. $\mathrm{A}_{\mathrm{A}}$ is the $A_{517}$ of a sample without DPPH (blank).

\section{$\beta$-carotene/linoleic acid assay}

The $\beta$-carotene-linoleic acid assay was performed as reported by TEPE et al. [18] with some modifications. A stock solution of $\beta$ carotene-linoleic acid mixture was prepared as follows: $0.5 \mathrm{mg} \beta$-carotene was dissolved in $1 \mathrm{~mL}$ of chloroform and $25 \mu \mathrm{L}$ linoleic acid and $200 \mathrm{mg}$ of Tween 20 were added. The chloroform was removed under nitrogen. The volume of the resulting mixture was completed up to $100 \mathrm{~mL}$ with aerated water. Aliquots $(2.5 \mathrm{~mL})$ of this reaction mixture were dispensed into different test tubes containing $300 \mu \mathrm{L}$ of test samples in the concentrations of 10.0, 20.0, 40.0, 80.0 and 160.0 $\mu \mathrm{g} / \mathrm{mL}$ for the ME and IP samples and concentrations of $48.0,144.0,240.0$ and $336.0 \mu \mathrm{g} / \mathrm{mL}$ for the CAL, CAI, CAB and CAE samples. The absorbance in $470 \mathrm{~nm}$ was measured in the initial time of the reaction and after two hours. The BHT, tanic acid, naringenin and quercetin were used as standards in concentrations of 10.0, 20.0, 40.0, 80.0 and $160.0 \mu \mathrm{g} / \mathrm{mL}$. A control containing $300 \mu \mathrm{L}$ of methanol and $2.5 \mathrm{~mL}$ of the above mixture was prepared. The tubes were placed at $45^{\circ} \mathrm{C}$ in a water bath for two hours. All the tests were conducted in triplicate. The inhibition of peroxidation of the solutions tested was calculated using the following equation:

Inhibition of peroxidation $(\%)=(\beta-$ carotene content after $2 \mathrm{~h}$ assay/initial $\beta$-carotene content) x 100.

\section{Stability Study}

The stability of the working standard solutions was tested at $22{ }^{\circ} \mathrm{C}$ (working temperature) and $-20{ }^{\circ} \mathrm{C}$ (storage temperature). The stability of substances in the samples was evaluated during all the storage steps (i.e. at room temperature and at $-20{ }^{\circ} \mathrm{C}$ ). Stability was defined as being less than $2 \%$ loss of the initial drug concentration in the stated time.

\section{Results and Discussion}

\section{General}

The substances isolated from $C$. adamantium leaves collected in the flowering stage are here described for first time. Compounds 1-4 and 6 were characterized as flavanones and 5 and 7-9 as chalcones: 7-hydroxy-5-methoxy-flavanone (1), 7-hydroxy-5methoxy-6-methylflavanone (2), 5,7-dihydroxy-6-methylflavanone (3), 5,7-dihydroxy8-methylflavanone (4), 2',4'-dihydroxy-6'methoxychalcone (5), 5,7-dihydroxy-6,8-dimethylflavanone (6), 2',4'-dihydroxy-6'-methoxy-5'-methylchalcone (7), 2'.4'-dihydroxy-6'-methoxy-3'-methylchalcone (8) and 2 ', 4 ' - dihydroxy-6' - methoxy-3', 5 ' dimethylchalcone (9). 
Quantification of flavanones and chalcone

A number of preliminary HPLC experiments employing samples of $C$. adamantium leaves were performed to establish optimal conditions for HPLC analysis of this species.

HPLC analysis showed baseline separation for the compounds under consideration. The observed retention time to isolate compounds is shown in Table 1 . The quantification of compounds $2,3,4,5,6,7$ and 9 was made by comparison of their retention time with those of authentic standards and by standards addition in the same samples analyzed using HPLC. The photodiode array detector was employed in the samples in the determination of compounds and in the evaluation of interference in all peaks of the chromatograms. The analysis of the precision of the assay intra- day CVs were less than $\pm 2 \%$.

The compounds were stable in the working solutions after $24 \mathrm{~h}$ at $22{ }^{\circ} \mathrm{C}$, two months at $20^{\circ} \mathrm{C}$. The calibration curves were determined by linear regression (Table 1). Average standard errors for the peak areas of replicate injections $(n=3)$ were smaller than $2 \%$ showing good repeatability of the calibration curve. The peak areas for the calibration curve of compound 2 were determined at $284 \mathrm{~nm}$, compounds 3 and 4 at $296 \mathrm{~nm}$, compound $\mathbf{5}$ at $350 \mathrm{~nm}$, compound $\mathbf{6}$ at $299 \mathrm{~nm}$, and compounds 7 and 9 at $340 \mathrm{~nm}$.

Table 2 shows the contents of the compounds identified in samples in distinct cities during the fruit bearing stage. The data displayed showed that CAL contains larger amounts of the flavanones and chalcones followed by $\mathbf{C A B}$, CAI and CAE. The samples show higher amounts of the chalcones than that of flavanones.

Though the flavanones and chalcones contents showed a difference quantitatively in different samples, those consumed by the Bela Vista, Bonito and Jardim populations exhibited higher contents, mainly chalcones $\mathbf{7}$ and $\mathbf{9}$. Studies of the latter exhibited individually activity against Staphylococcus aureus and Bacillus cereus and increased activity in synergy with the antibiotics berberin and

Table 1. Retention time and regression data of calibration curve for quantitative determination by HPLC.

\begin{tabular}{ccccccc}
\hline Compounds & $\begin{array}{c}\text { Retention time } \\
\left(\text { min. } \pm \text { S.D. } D^{\mathrm{a}} \text { ) }\right.\end{array}$ & $\mathrm{LR}^{\mathrm{b}}$ & $\mathrm{B}^{\mathrm{c}}$ & $\mathrm{A}^{\mathrm{d}}$ & $\mathrm{R}^{\mathrm{e}}$ & $\mathrm{N}^{\mathrm{f}}$ \\
\hline 2 & $15.33 \pm 0.16$ & $0.04-10.80$ & 4.95919 .106 & -161369.02552 & 0.99962 & 6 \\
3 & $22.02 \pm 0.24$ & $0.16-4.10$ & 6.58015 .106 & -1.3073 .106 & 0.99889 & 5 \\
4 & $23.51 \pm 0.27$ & $0.12-3.67$ & 1.80351 .107 & -2.37114 .106 & 0.99978 & 5 \\
5 & $24.70 \pm 0.21$ & $0.20-5.00$ & 5.60768 .106 & -1.29557 .106 & 0.99825 & 5 \\
6 & $26.22 \pm 0.26$ & $0.21-5.00$ & 5.15469 .106 & -564964.75892 & 0.99921 & 5 \\
7 & $30.18 \pm 0.25$ & $5.65-22.66$ & 500747.0648 & -35037.81908 & 0.9995 & 5 \\
9 & $33.67 \pm 0.24$ & $3.00-28.00$ & 507205.62017 & -22757.06765 & 0.99860 & 5 \\
\hline
\end{tabular}

aS.D.: standard deviations. bLR: linear range. Linear regression. formula: $\mathrm{y}=\mathrm{A}+\mathrm{Bx}$. where $\mathrm{y}=$ peak areas ratio. ${ }^{\mathrm{c} B}$ : slope. ${ }^{\mathrm{d}} \mathrm{A}$ : intercept. $\mathrm{x}: \mu \mathrm{g}$. ${ }^{\mathrm{R}} \mathrm{R}$ : correlation coefficient. ${ }^{\mathrm{f}} \mathrm{N}$ : number of samples. Compounds: 7-hydroxy-5methoxy-6-methylflavanone (2), 5,7-dihydroxy-6-methylflavanone (3), 5,7-dihydroxy-8-methylflavanone (4), 2',4'-dihydroxy-6'-methoxychalcone (5), 5,7-dihydroxy-6,8-dimethylflavanone (6), 2',4'-dihydroxy-6'-methoxy5'-methylchalcone (7) and 2',4'-dihydroxy-6'-methoxy-3',5'-dimethylchalcone (9).

Table 2. Contents of compounds identified in the methanolic extracts from the $C$. adamantium leaves.

\begin{tabular}{|c|c|c|c|c|c|c|c|}
\hline \multirow{2}{*}{$\begin{array}{c}\text { Compounds } \\
\text { Samples }\end{array}$} & \multicolumn{5}{|c|}{ Flavanones $\left(\mathrm{mg} / \mathrm{g} \pm\right.$ S.D. $\left.{ }^{\mathrm{a}}\right)$} & \multicolumn{2}{|c|}{ Chalcones $\left(\mathrm{mg} / \mathrm{g} \pm\right.$ S.D. $\left.{ }^{\mathrm{a}}\right)$} \\
\hline & 2 & 3 & 4 & 5 & 6 & 7 & 9 \\
\hline CAI & $6.72 \pm 0.44$ & $22.82 \pm 0.95$ & $6.38 \pm 0.30$ & $5.74 \pm 0.41$ & $3.71 \pm 0.28$ & $82.42 \pm 5.01$ & $11.24 \pm 0.78$ \\
\hline $\mathrm{CAB}$ & $8.27 \pm 0.42$ & $12.74 \pm 0.33$ & $6.26 \pm 0.24$ & $6.39 \pm 0.12$ & $3.49 \pm 0.09$ & $94.70 \pm 2.81$ & $15.01 \pm 0.35$ \\
\hline CAL & $10.12 \pm 0.11$ & $30.17 \pm 0.62$ & $10.42 \pm 0.21$ & $10.62 \pm 0.25$ & $6.37 \pm 0.24$ & $194.66 \pm 2.32$ & $31.32 \pm 0.76$ \\
\hline CAE & & $12.67 \pm 0.28$ & $2.95 \pm 0.03$ & & $4.67 \pm 0.23$ & & \\
\hline
\end{tabular}

aS.D.: standard deviations. 
tetracycline [4]. The samples from Bela Vista, Bonito and Jardim show chalcone 5, which have anti-HIV-1 protease activity. Although, the sample consumed by the Dourados population does not showed the presence of $\mathbf{2 , 5 , 7}$ and $\mathbf{9}$.

Hence supposing that the production and concentration of the secondary metabolites in the guavira leaves can be influenced by environmental strain of each region, these changes might be associated with the variation of the medicinal properties of the vegetables in each municipality.

Determination of the free radical scavenging activity

The use of 2.2-diphenyl-1-picryl-hydrazyl (DPPH) as a reagent for screening the antioxidant activity of molecules has been reported [19]. In this assay the scavenging of the DPPH radical is followed by monitoring the decrease in absorbance at $517 \mathrm{~nm}$, which occurs due to the reduction by antioxidants and has been used to assess the ability of phenolic compounds to transfer labile $\mathrm{H}$ atoms to radicals [1].

The antioxidant activity of ME and IP using the DPPH assay displayed in figure 1 shows that the $C$. adamantium leaves exhibit very good radical scavenging activities. But only the concentration from the $80.0 \mu \mathrm{g} / \mathrm{mL}$ samples showed similar activity with quercetin and tanic acid standards and that more active than BHT and naringenin, all in the same concentration. The ME and IP show the highest activity with $91.6 \%$ and $88.9 \%$ at $160.0 \mu \mathrm{g} / \mathrm{mL}$ and quercetin standard of $94.6 \%$ in some concentrations.

The CAI and CAB samples showed an scavenging effect larger than $80.0 \%$ as of 480.0 $\mu \mathrm{g} / \mathrm{mL}$, while CAL and CAE showed that the scavenging effect was larger than $80.0 \%$ as of 160.0

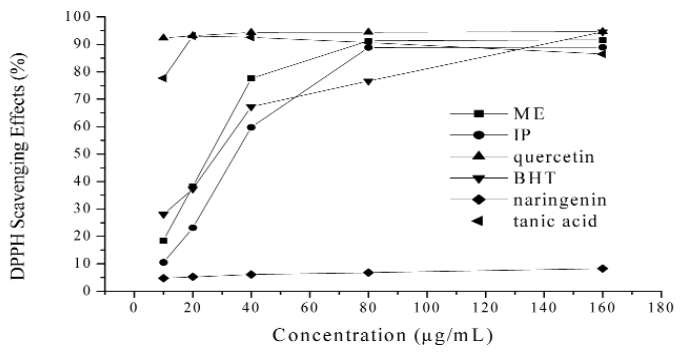

Figure 1. Free radical scavenging activity of ME, IP, quercetin, BHT, naringenin and tanic acid. $\mu \mathrm{g} / \mathrm{mL}$. The antioxidant activity in all extracts in $160.0 \mu \mathrm{g} / \mathrm{mL}$ were lower than the quercetin standard in $160.0 \mu \mathrm{g} / \mathrm{mL}$ (94.6 \%), except the CAL sample that showed the same scavenging effect as quercetin in the lower concentration. The analysis of the precision of the assay intra- day CVs were less than $\pm 2 \%$, except for CAI $(160.0 \mu \mathrm{g} / \mathrm{mL})$ and CAB $(160.0 \mu \mathrm{g} / \mathrm{mL}), 5 \%$ and $6 \%$, respectively.

The compounds analyzed by extracts did not show direct correlation with antioxidant activity, except the CAL sample.

The antioxidant activity of phenolics is mainly due to their redox properties which make them act as reducing agents, hydrogen donors and singlet oxygen quenchers. The chemical nature of the flavonoids depends on structural class, degree of hydroxylation, other substitutions and conjugations [20].

Studies of structure-radical scavenging activity of phenolic compounds in Chinese plants showed that the lowest antiradical activity of the flavonoids was attributed to the flavanones and isoflavanones, therefore the antioxidant activity depends on the number and position of hydroxyl groups in rings $\mathrm{A}$ and $\mathrm{B}$ as well as 2,3-double bond (insaturation) and the 4-oxo group in ring $\mathrm{C}$ [21].

\section{Inhibitory effect on lipid peroxidation}

In the $\beta$-carotene/linoleic acid assay the antioxidant capacity is determined by measuring the inhibition of the organic compounds and the conjugated diene hydroperoxides arising from linoleic acid oxidation [18]. This assay has been used to simulate the oxidation of the membrane lipid components in the presence of antioxidants inside the cell [22]. The results obtained from extracts of $C$. adamantium leaves are exibited in figure 2.

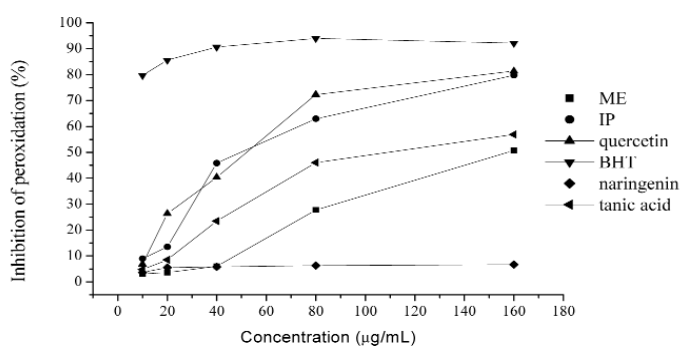

Figure 2. Antioxidant activity of ME, IP, quercetin, BHT, naringenin and tanic acid by $\beta$ carotene/linoleic acid system. 
Sample ME shows low inhibition of peroxidation $50.8 \%$ in a concentration of 160.0 $\mu \mathrm{g} / \mathrm{mL}$, while the IP shows appreciable inhibiton of $79.7 \%$ with values similar to the quercetin $(81.3 \%)$, higher than tanic acid $(56.9 \%)$ and naringenin $(6.7 \%)$ and lower than BHT $(92.1 \%)$ all the same concentrations.

The samples collected in distinct cities exhibited antioxidant activity based on inhibition of peroxidation assay ranging from 14.6-94.2\% in a concentration of $48-336 \mu \mathrm{g} / \mathrm{mL}$ and a lower variation between samples.

Samples CAL, CAI, CAE and CAB in the $144.0 \mu \mathrm{g} / \mathrm{mL}$ concentrations show inhibition of peroxidation of $89.8,84.8,66.3$ and $46.5 \%$, respectively. These results indicate that of the $C$. adamantium leaves the samples CAL and CAI exhibited appreciable inhibition of peroxidation compared to BHT of $160.0 \mu \mathrm{g} / \mathrm{mL}(92.1 \%)$. The analysis of the precision of the assay intra- day CVs were less than $\pm 5 \%$.

Analysis of the structure-antioxidant activity relationship of the standards shows that the lipophilic compounds with the BHT are more potent that the hydrophilic compounds such as quercetin and tanic acid, as well as compounds of low insaturation and absence of the lipophilicity substituent with naringenin. Compounds 3, 4, 6, 7 and 9 show correlation which enhances the inhibition of peroxidation, mainly chalcones $\mathbf{7}$ and $\mathbf{9}$ in the CAL, CAI and CAB samples and flavanones 3, 4, 6 with methyl substituents in all samples.

\section{Determination of total phenolic content}

The results showed CAL $(21.2 \mathrm{mg} / \mathrm{g})$ and CAE $(15.9 \mathrm{mg} / \mathrm{g})$ with high phenolic content in comparison to CAI $(9.0 \mathrm{mg} / \mathrm{g})$ and CAB $(7.2$ $\mathrm{mg} / \mathrm{g}$ ). The precision analysis of the assay intraday CVs was less than $\pm 5 \%$ showing reproductibility of the extraction procedure. The compounds identified in the samples, in general, did not show direct correlation to phenolic contents. The CAL sample showed direct correlation to the compounds under consideration in relation to phenolic content. The CAE, CAB and CAI samples did not show this profile.

The antioxidant activity by inhibition of peroxidation shows correlation to phenolic contents, except the CAE sample. And also with antioxidant activity by DPPH radical scavenging in a concentration of $160.0 \mu \mathrm{g} / \mathrm{mL}$, but in higher concentration the CAI sample showed no correlation.

These results showed that in high concentrations, the extract exhibited high antioxidant activity and that as it increases the concentration of the extract, the activity is practically constant, even with a variation of phenolic content. The higher antioxidant activity showed in the extracts might be associated with other compound phenolics that were not isolated, mainly the CAE samples, which show higher phenolic content and lower phenolic content among the compounds isolated.

\section{Conclusions}

On the basis of the results it is suggested that the Campomanesia adamantium leaves evaluated here can be used as a source of natural antioxidant. However, the results showed a distinct composition quantitave in this vegetable of some species collected in distincts cities, but a similar chemical composition qualitative (except the Dourados sample). The different samples exhibited a range of total phenolics contents variyng from 7.2 to $21.2 \mathrm{mg} / \mathrm{g}$. Phenolic compounds seem to have important role in stabilizing lipid oxidation and to be associated with antioxidant activity. The phenolic compounds may contribute directly to antioxidative action. Therefore, further work could be done on the isolation and purification of the active components from the crude extracts of Campomanesia species for showing the mode of action of them.

\section{Acknowledgements}

We thank the Fundação de Apoio ao Desenvolvimento do Ensino, Ciência e Tecnologia do Estado de Mato Grosso do Sul (FUNDECT) for financial support. We also thank to Capes for grant given to I.D.C., and to CNPq for grant given to R.G.C. and J.R.M. We also thank Marcos Sobral for the identification of C. adamantium.

Received June 162008

Accepted November 032008 
I. D. Coutinho, R. G. Coelho, V. M. F. Kataoka, N. K. Honda, J. R. M. Silva, W. Vilegas and C. A. L. Cardoso. Determinação de compostos fenólicos e avaliação da capacidade antioxidante das folhas de Campomanesia adamantium.

Resumo: Cinco flavanonas e três chalconas foram isoladas das folhas de Campomanesia adamantium Berg. (Myrtaceae). O teor desses compostos foram determinados por CLAE. O teor de compostos fenólicos também foi determinado. O monitoramento da atividade antioxidante foi feito pela inibição da peroxidação usando o sistema do ácido linoleico e método do radical livre 2,2-difenil-1-picrilhidrazila - DPPH•. As espécies vegetais foram coletadas em 4 cidades diferentes do estado de Mato Grosso do Sul, Brasil. As diferentes amostras exibiram uma variação de 4,67-232,35 mg/g chalconas e 15,62-50,71 mg/g flavanonas e teor de compostos fenólicos de 7,24-21,19 mg/g ácido gálico. Todos os extratos exibiram alta atividade antioxidante com uma variação do efeito radical livre (DPPH) de 52,0-92,2 \% e da inibição da oxidação do ácido linoleico de 14,6-94,2\%.

Palavras-chave: Campomanesia adamantium; chalconas; flavononas; atividade antioxidante.

\section{References}

[1] A. Djeridane, M. Yousfi, B. Nadjemi, D. Boutassouna, P. Stocker, and N. Vidal, Food Chemistry 97(2006) 654.

[2] P. Hodek, P. Trefil, M. Stiborová, Chemico-Biological Interactions 139 (2002) 1.

[3] M. Cabrera, M. Simoens, G. Falchi, M. L. Lavaggi, O. E. Piro, E. E. Castellano, A. Vidal, A. Azqueta, A. Monge, A. L. Ceráin, G. Sagrera, G. Seoane, H. Cerecetto, M. González, Bioorganic \& Medicinal Chemistry 15 (2007) 3356.

[4] Z. Nowakowska, European Journal of Medicinal Chemistry 42 (2007) 125.

[5] S. Tewtrakul, S. Subhadhirasakul, J. Puripattanavong, T. Panphadung, Journal of Science Technology 25 (2003) 503.

[6] H. Lorenzi, L. Bacher, M. Lacerda, S. Sartori, Frutas brasileiras e exóticas cultivadas: (de consumo in natura). Instituto Plantarum de Estudos da Flora, São Paulo, Brazil, 2006.

[7] M. W. Biavatti, C. Farias, F. Curtius, L. M. Brasil, L. Hort. L. Schuster, S. N. Leite, S. R. T. Prado, Journal of Ethnopharmacology 93 (2004) 385.

[9] C. A. L. Cardoso, W. Vilegas, A. Barison, N. K. Honda, Journal of Agricultural Food Chemistry 50 (2002) 1465.

[9] C. A. L. Cardoso, N. K. Honda, A. Barison, Journal of Pharmaceutical and Biomedical Analysis 27 (2002) 217.

[10] P. K. Agrawal, Carbon-13 NMR of flavonoids. Elsevier Science Publishing, New York, USA, 1989.

[11] H. Itokawa, M. Morita, S. Mihashi, Phytochemistry 20 (1981) 2503
[12] W. He, Y. Li, J. Tang, F. Luan, J. Jin, Z. Hu, Z., International Journal of Biological Macromolecules 39 (2006) 165.

[13] K. Mustafa, N. B. Perry, R. T. Weavers, Biochemical Systematics and Ecology 33 (2005) 1049.

[14] K. E. Malterud, T. Anthonsen, G. B. Lorentzen, Phytochemistry 16 (1977) 1805.

[15] N. Tanrisever, F. R. Fronczek, N. H. Fischer, G. B. Williamson, Phytochemistry 26 (1987) 175.

[16] Silva, J. R. M., Cardoso, A. L. C., Coelho, R. G., Honda, N. K., Isolamento e identificação de chalconas e avaliação da atividade antioxidante no extrato hexânico dos frutos de Campomanesia pubescens. In XVI Congreso Italo-latinoamericano de etnomedicina. La Plata, Argentina, SILAE, Press (2007) 349.

[17] M. K. Mokbel, F. Hashinaga, Food Chemistry 94 (2006) 529.

[18] K. Tepe, D. Daferera, A. Sokmen., M. Sokmen, M. Polissiou, Food Chemistry 90 (2005) 333.

[19] D. Villaño, M. S. Fernández-Pachón, M. L Moyá, A. M. Troncoso, M. C. García-Parilla, Talanta 71 (2006) 230.

[20] D. Di Majo, M. Giammanco, M. La Guardia, E. Trípoli, S. Giammanco, E. Finotti, Food Research International 38 (2005) 1161.

[21] Y. Cai, M. Sun, J. Xing, Q. Luo, H. Corke, Life Sciences 78 (2006) 2872.

[22] A. T. Mata, C. Proença, A. R. Ferreira, M. L. M. Serralheiro, J. M. F. Nogueira, M. E. M. Araújo, Food Chemistry 103 (2007) 778. 